Revista de la red interuniversitaria de estudios sobre las literaturas rioplatenses contemporáneas en Francia

6 | 2011

Juan José Saer. archivos, memoria, critica

\title{
La génesis de un final
}

Dardo Scavino

\section{OpenEdition}

Journals

Edición electrónica

URL: http://journals.openedition.org/lirico/190

DOI: 10.4000/lirico.190

ISSN: 2262-8339

Editor

Réseau interuniversitaire d'étude des littératures contemporaines du Río de la Plata

Edición impresa

Fecha de publicación: 1 diciembre 2011

Paginación: 79-89

ISBN: 2-9525448-5-9

ISSN: 2263-2158

\section{Referencia electrónica}

Dardo Scavino, «La génesis de un final », Cuadernos LIRICO [En línea], 6 | 2011, Puesto en línea el 01 julio 2012, consultado el 09 mayo 2019. URL : http://journals.openedition.org/lirico/190 ; DOI 10.4000/lirico. 190

\section{(c) (i) $\ominus$}

Cuadernos LIRICO está distribuido bajo una Licencia Creative Commons Atribución-NoComercial-

SinDerivar 4.0 Internacional. 


\title{
LA GÉNESIS DE UN FINAL
}

\author{
DARDO SCAVINO \\ Univeristé de Versailles
}

$\mathrm{P}$ ermítanme que aborde estas cuestiones a través de una lectura del último poema de El arte de narrar: "Dama, el día". En la segunda estrofa leemos que la dama es un "animal / nupcial / que el pico rojo esculpe / a su imagen..." Un día, no cabe duda, Saer escribió por primera vez estos versos aunque ignoro si lo hizo así desde el principio o si los reescribió varias veces antes de la versión acabada. Estos cuatro versos, no obstante, son la reescritura de otros que nadie ignora y que se encuentran en el primer libro del Génesis: "Dios creó al hombre a su imagen, / a imagen de Dios los creó, / macho y hembra los creó" (Gen 1,27). Ustedes van a decirme que no es casual que yo haya escogido una reescritura de este libro a la hora de abordar la cuestión de la generación de un texto y de la crítica genética. Y obviamente no lo es. Como tampoco es azaroso que la cuestión de la génesis aparezca a propósito de la poïesis, vocablo que la Biblia griega empleaba para referirse a la creatio. Cada vez que hay poïesis hay generación, y cada vez que hay generación, hay genitores: el Génesis, de hecho, es el libro genealógico por excelencia. Pero dejo este punto en suspenso para interrogarme sobre las correcciones que introdujo Saer en el célebre terceto de este libro convertido, a partir de ahora, en un manuscrito provisorio de sus versos. Hay, por lo menos, tres enmiendas: "el pico rojo" en lugar de "Dios", "esculpe" en lugar de "creó" y finalmente la "dama" y "animal nupcial" en lugar de "macho y hembra".

No puedo decir exactamente de dónde proviene la expresión "pico rojo", pero tengo algunas conjeturas. Saer hablaba ya de una "punta roja o revés de terciopelo" en un poema sobre Príapo y de un "dedo rígido y rojo como un pene" en otro sobre Narciso. El santafesino estaría cor-

\footnotetext{
${ }^{1}$ Juan José Saer, El arte de narrar, Buenos Aires, Planeta, 2000, p. 155.
} 
rigiendo de este modo el primer libro del Génesis para sustituir a Dios por el Falo, lo que no tiene nada de extraño ya que él había frecuentado esa tradición blasfematoria y obscena de los epigramas priápicos. Pero antes de apresurarnos a concluir que se trata, por este motivo, de una reescritura satírica del Antiguo Testamento, me permito recordarles que en los inicios de la era cristiana existió un vasto debate acerca de quién ocupaba el lugar del origen: si Dios o Príapo. Para neoplatónicos como Porfirio de Tiro y hasta para algunos gnósticos cristianos como Justino ${ }^{2}$, Príapo era el símbolo de ese Lógos primordial que llamaban también spermátikos. Si el Dios de la religión judeo-cristiana es el Padre, lo es por sus genitales. Y a ningún autor antiguo, fuese cristiano o pagano, se le hubiese ocurrido olvidarlos a propósito del Génesis. Los debates dentro y fuera del cristianismo acerca del origen, de la creatio o de la interpretación del Génesis, pueden leerse también como una serie de reescrituras de un texto: de correcciones, de rectificaciones o de glosas.

Pasemos entonces a la segunda enmienda que Saer introduce en los versos veterotestamentarios: "esculpe" en lugar de "creó". Nadie ignora de dónde proviene ese verbo: Saer está poniendo al "pico rojo" en el lugar de Pigmalión, el escultor chipriota, y a la dama en el lugar de su amada, Galatea. El santafecino propondría incluso una versión psicótica de este artista apasionado con el asesino serial de La pesquisa. Pero el escultor popularizado por las Metamorfosis de Ovidio ya había obtenido un papel protagónico en la tradición cortés y en el Roman de la rose de Jean de Meung, quien le consagró un canto entero sin olvidar compararlo, como resultaba habitual, con otro amante apasionado: Narciso. Ambos personajes ovidianos asumieron muchas veces el estatuto de alegoría del Dios cristiano. Los tres amaban, después de todo, a las criaturas que crearon "a su imagen" y por eso Sor Juana Inés de la Cruz iba a escribir un auto sacramental intitulado El Divino Narciso. El verbo esculpir sustituye entonces el crear del Génesis pero también imaginar, figurarse o fantasear. Y la elección de Pigmalión no tenía otro significado en esa tradición pneumo-fantasmalógica estudiada por el joven Giorgio Agamben: la amada, según esta poesía, es un fantasma del amante.

Llegamos así a la tercera enmienda introducida por Saer en los tres versos del Génesis. El santafecino tacha la expresión "macho y hembra" y la sustituye por "Dama" y "animal nupcial". La elección de esta expre-

\footnotetext{
${ }^{2}$ Maurice Olender, "Éléments pour une analyse de Priape chez Justin le Gnostique" in Hommages à Maarten Vermaseren II, Leiden, E.J. Brill, 1978, p. 874-895.
} 
sión también podría explicarse a partir del hipotexto genético. Dios llevó a todos los animales ante el hombre para que les diera un nombre. Y el hombre los nombró uno por uno. Pero entre ellos no encontró, según la traducción española, "ninguna ayuda apropiada" (Gen 2, 20). Así que Dios lo hizo caer en un sueño muy profundo y mientras dormía formó a la mujer a partir de una costilla. Entre todos los animales, entonces, la mujer es el "animal nupcial", labrado durante el sueño del hombre. Porque no habría que olvidar que el adjetivo nupcial no es sólo un sinónimo de marital sino también un derivado de nube, vocablo que Saer suele asociar con los fantasmas. Si la mujer es el "animal nupcial", el "animal obnubilado" sería, en su caso, el hombre.

Muchos teólogos, en efecto, trataron de resolver aquella flagrante contradicción del Génesis sin resultados convincentes: Dios los había creado primero macho y hembra, y resulta ser que más tarde se vio obligado a formar a la mujer durante la siesta del primero. Saer pareciera suministrarnos una solución de compromiso entre ambas variaciones: ya no tenemos un Dios que crea ambos sexos sino un sexo que sueña al otro. O un "pico rojo", si prefieren, que "esculpe" a esa dama "a su imagen", semejanza que los psicoanalistas, con Lacan a la cabeza, abordan muy a menudo citando una ecuación de Otto Fenichel: Girl $=$ Phallus $^{3}$. La dama no lo tiene porque lo es. La advertencia que el poeta le dirige a la dama al principio del poema, esa glosa del carpe diem horaciano, puede leerse entonces como un anuncio del destino de caída, flaccidez y arruga común al órgano y la joven.

\section{II}

Nos remontamos así a la génesis de una sola frase y al proceso de correcciones y sustituciones cuyo desenlace serían los versos de Saer. ¿Pero no podría interpretarse el propio poema como un proceso semejante que va desde su génesis, el incipit, hasta su juicio final, el excipit? Recuerden el consejo de Roland Barthes a los estudiantes de Letras en aquel artículo intitulado, y no por casualidad, "Par où commencer?" Barthes proponía “establecer primero los dos conjuntos límites, el inicial y el terminal", y examinar el proceso de transformaciones, o correcciones, gracias al cual el texto pasa de uno a otro ${ }^{4}$.

\footnotetext{
${ }^{3}$ Otto Fenichel, The Psychoanalytic Theory of Neurosis, London, Odges, 1999, p. 80.

${ }^{4}$ Roland Barthes, Le degré zéro de l'écriture, Paris, Seuil, "Point Essais", 1972, p. 141.
} 
Empecemos entonces por el incipit de donde proviene el título del poema: "Dama, el día / declina..." Este día horaciano encierra una analogía proporcional: el día es a la noche lo que la vida a la muerte. El verbo declina aparece como una advertencia acerca de la inminencia de ese anochecer, de esa muerte, de esa oscuridad y, en especial, de esa caída.

Encontramos estas mismas oposiciones al final, en el excipit. Sólo que Saer reescribe esta vez los envíos del perigordino Bertran de Born, quien solía encomendarle a su infatigable juglar, Papiol, la tarea de hacerles llegar a las damas o los caballeros sus respectivas declaraciones de amor o de guerra. "Vai, Papiol, ades tost e correns, / A Transinhac...", le ordenaba a su vasallo: "Ve, Papiol, corriendo sin parar, a Transinhac..." O incluso: "Papiol, lleva corriendo este mensaje: / Ricardo es un león, / y Felipe de Francia un carnero / que se deja esquilar sin decir nada"6. Estos envíos que remataban los sirventés y los cansos del vizconde de Hautefort iban a ser adoptados por muchos otros trovadores y por el propio Alighieri. Saer prefiere concluir su poema, y su libro, encomendándole esta misión al Tiempo:

Papiol (Tiempo), lleve

estas líneas a alguna

parte, de parte

de uno

que vino

$\mathrm{y}$

clic

se fue. ${ }^{7}$

El verbo declina del incipit anunciaba ya el excipit: no sólo por la homofonía parcial con el clic o el sonido onomatopéyico del interruptor de la luz sino también por el caligrama del declive formado por los versos finales dispuestos en escalera. El principio y el final del poema evocan entonces el día y la noche, la luz y la oscuridad, la elevación y el descenso.

Hay sin embargo una diferencia entre el incipit y el excipit. Si el primero se presenta bajo la forma de una advertencia a la dama, el segundo es una despedida del amante. La segunda estrofa nos ofrece un

\footnotetext{
${ }^{5}$ Juan José Saer, El arte de narrar, op. cit., p. 155.

${ }^{6}$ Pierre Bec (comp.), Anthologie de troubadours, Paris, 10/18, 1979, p. 212.

${ }^{7}$ Juan José Saer, El arte de narrar, op. cit., p. 156.
} 
principio de respuesta a esta nueva corrección. La "flor" sigue siendo aquí la metáfora de la dama e incluso va a permitirle a Saer asociarla, en la siguiente estrofa, con su inseparable "abeja", para completar ese relato de la polinización que algunos adultos convierten en alegoría infantil del acto sexual. Sólo que esta vez ya no se insiste en el decadencia inexorable de la flor desde su lozana firmeza hasta su marchitamiento sino en su reaparición anual, "fresca otra vez" en "cada octubre". Fantasma del deseo masculino, la dama recobra su belleza cada vez que el "pico rojo" renace entre las cenizas. O como escribe Saer en la tercera estrofa del poema:
Dama, que el torbellino inadvertido y lento pone en la punta en flor para atrapar la abeja somnolienta y semiciega, que cumple con su rito, y cae después, reseca, en el río oscuro. ${ }^{8}$

Saer reescribe una vez más esta estrofa introduciendo esta vez una inversión de la imagen que los poetas barrocos solían proponer de la presunta perpetuidad:

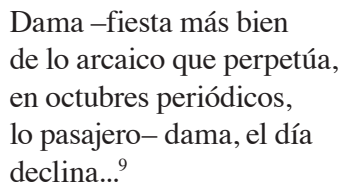

En lugar de recordarnos la vanidad de lo perpetuo, a la manera de Garcilaso o Quevedo, Saer prefiere destacar la perpetuación de lo vano: la dama no declina sino que reaparece en cada primavera. Quien declina, quien "cae" en el "río oscuro" o se convierte en "polvo del camino", es ahora el amante, instrumento ciego, o semiciego, de lo "arcaico", es decir, de lo que se encuentra en la $\operatorname{archê~o~el~origen.~Y~ustedes~re-~}$ cordarán seguramente que estos mismos ciclos de lo arcaico tenían un papel central en su novela El entenado. Los colastiné, precisamente, no parecían adorar ninguna divinidad pero se convertían en las marionetas dóciles de este "torbellino inadvertido y lento". Algo semejante le ocurría, sin ir más lejos, a Príapo en el poema homónimo de Saer, y

\footnotetext{
${ }^{8}$ Ibid., p. 155.

${ }^{9}$ Ibid., p. 156.
} 
por eso el poeta lo califica allí de "violador" (aunque la lengua popular rioplatense hubiese preferido ese florido sustituto de "violeta" que Saer introduce en "Dama, el día"). Príapo, escribe Saer,

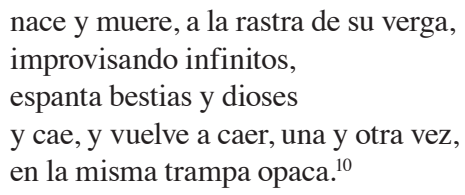

Saer inserta incluso algunas correcciones llamativas en la quinta estrofa del poema. Cuando habla de la pelea entre "materia y deseo""11, por ejemplo, está poniendo el verbo "pelean" en el lugar de "esculpe", sugiriéndonos así que la fantasía labra a la dama a partir de esa materia nebulosa que él mismo había llamado alguna vez "mancha Rorschach"12. Pero en esta misma quinta estrofa el escritor introduce otra enmienda: el moscardón, escribe, "confundía / mundo y deseo..."13 De modo que Saer no sólo sustituye el verbo "esculpe" por "pelean" sino que además pone al "mundo" allí donde se encontraba, unos versos antes, la "dama". Quienes conozcan su obra no deberían sorprenderse ante una permutación semejante: el mundo es, al igual que la dama, un fantasma, y por eso Tomatis no cesaba de temer su inminente desmoronamiento cuando se hundió en su depresión (“...el famoso aditamento desapareció de un día para otro entre mis piernas" y "una vez retirado el deseo fue instalándose, cada día menos lenta, la disgregación"14).

Habrán notado entonces que las oposiciones binarias en torno a las cuales se organiza este poema son de lo más ordinarias: el día y la noche, la luz y la oscuridad, la vida y la muerte, el venir y el irse,

\footnotetext{
${ }^{10}$ Ibid., p. 109.

${ }^{11}$ Ibid., p. 156.

${ }^{12}$ Juan José Saer, Nadie nada nunca, México, Siglo XXI, 1980, p. 10.

${ }^{13}$ Juan José Saer, El arte de narrar, op. cit., p. 156.

${ }^{14}$ Juan José Saer, Lo imborrable, Buenos Aires, Alianza, 1993, p. 170. Algunos textos psicoanalíticos, dicho sea de paso, ya habían establecido un vínculo semejante: hay una angustia suscitada por esa desaparición del deseo y el consecuente derrumbe del mundo. Aphanisis, la llamaba Ernst Jones, retomando la raíz griega que alude a lo que aparece, lo que sale a la luz y también a los fantasmas. Fading, parafraseaba Jacques Lacan, retomando ese verbo inglés sinónimo de marchitarse, desaparecer o debilitarse. Pero no es en modo alguno casual que unos y otros hayan tenido la idea de emparentar la dama y el mundo: tanto el vocablo latino mundus como su sinónimo griego, cósmos, aludían a los implementos de belleza femeninos antes de referirse a la totalidad de los seres.
} 
el aparecer y el desaparecer, la presencia y la ausencia, la primavera y el otoño, la elevación y el descenso, los actos de empezar y acabar, pero también la turgencia y la desentumescencia del miembro viril, derrumbe metaforizado por los desmoronamientos post coitum del "moscardón" y la "abeja". Como sucede en muchas culturas -algunos se atreverían a decir incluso: en todas- estas oposiciones no cesan de aludir en "Dama, el día" a las indomeñables tensiones y distensiones del susodicho aditamento. Y a esto hacía también alusión Lacan cuando aseguraba que la oposición binaria, el primer significante representa la aparición del sujeto; el segundo, en cambio, su angustioso fading.

"Dama, el día" empieza entonces con esta "dama" y su "día” y concluye con el poeta y su noche. Y hasta podría sostenerse que todo El arte de narrar acaba así: al final, no hay ninguna elucidación sino, por el contrario, la oscuridad más absoluta. ¿Y no es lo que anticipa Saer al final de la primera estrofa? El día, vuelve a decir, declina

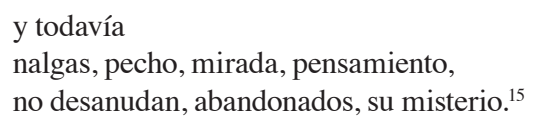

Confieso que cuando leí por primera vez estos versos pensé que el editor había cometido un error poniendo "no desanudan" en lugar de "no desnudan" y me pregunté quién guardaría el manuscrito de Saer para verificar la errata. El poeta acababa de evocar, después de todo, la desnudez de los cuerpos: siempre queda algo sin descubrir en ellos aunque se descubran por completo, y se trataría del misterio del deseo. Pero aun cuando hubiera aquí una errata, el verbo desanudar no dejaría de imponer su pertinencia: la estructura heurística de la narración-cuya analogía con la relación sexual se señaló más de una vez y se explotó hasta el hartazgo en el cine- nos invita a suponer que el misterio va a revelarse con el desenlace, el dénouement, de la historia. Para Saer, por el contrario, el nudo de esta historia nunca llega a desanudarse: al final, el misterio queda y el héroe, por el contrario, se va. La poética de Poe y Borges era teleológica y, en sentido estricto, apocalíptica: la significación de los elementos se revela retrospectivamente al final. Para Saer, por el contrario, no hay teleología alguna ni elucidación postrera: hay una simple interrupción, como lo sugiere el clic del interruptor de la luz. Y así decidió que fuera el desenlace de su Arte de narrar.

${ }^{15}$ Juan José Saer, El arte de narrar, op. cit., p. 155 
Hay sin embargo una pregunta que podríamos hacernos. Si "Dama, el día" es el último poema de este libro -el poema del final y acerca del final- ¿no deberíamos aplicar una vez más el consejo de Roland Barthes y constatar cómo comienza? Ustedes van a decirme, claro, que se trata de una recopilación de poesías que Saer escribió a lo largo de veintisiete años, si no más, y que no puede aplicársele el mismo criterio que a una novela, un cuento o incluso, como acabamos de ver, a un único poema. Pero no podemos descartar completamente esta hipótesis hasta no verificarla. El título del primer poema evoca literalmente su hipotexto: L'art romantique de Charles Baudelaire. Y el incipit nos indica incluso qué capítulo preciso se había propuesto reescribir Saer:

¡Pobre Petrus Borel! Con la señora Putifar y todo, se hundió en el cielo estrellado. ${ }^{16}$

Baudelaire le había dedicado un artículo a este escritor muerto unos años antes en Argelia, miembro del cenáculo de Gautier y de Nerval, a quien apodaban "el licántropo" debido a la maldición que agobiaba a uno de sus personajes y a su acentuada predilección por la novela gótica inglesa. Borel era además el autor de una novela, Madame Putiphar, en la que había reescrito casualmente otro episodio del Génesis: la historia de la esposa del guardia del faraón que acusó injustamente a José de haber querido abusar de ella después de que el esclavo hebreo se negara a ceder a sus avances. Sólo que el escritor frenetista sitúa este episodio en la Revolución francesa y lo rodea de cinco violaciones.

Tanto Baudelaire como Saer están aludiendo a otra muerte cuando muestran a Borel hundiéndose en la noche: se trata de la desaparición del escritor que va a caer en el olvido. Por momentos, Saer se limita a traducir a Baudelaire, a quien llama incluso Carlos en el cuarto verso. El poeta francés había recordado, apenas dos años después de la desaparición de Borel, que este novelista había sido "une des étoiles du sombre ciel romantique". Y concluía: "Étoile oubliée ou éteinte, qui s'en souvient aujourd'hui, et qui la connaît assez pour prendre le droit d'en parler si délibérément? ${ }^{17 "}$ Aprendamos, preconiza por su parte Saer en

\footnotetext{
${ }^{16}$ Ibid., p. 7.

${ }^{17}$ Charles Baudelaire, L'art romantique, Paris, Garnier-Flammarion, 1968, p. 327.
} 
el excipit del poema, "de Petrus Borel / aunque se haya, por fin, oscuro, hundido en el cielo, / y ninguna estrella lleve su nombre"18.

Baudelaire daba incluso muestras de haber tenido acceso a los manuscritos del desdichado Petrus ya que evocaba su caligrafía inusualmente inclinada hacia la izquierda y esos obsesivos procesos de escritura que lo llevaban a pasarse dos o tres horas en la redacción de la carta más banal a fuerza de tachaduras, enmiendas y rectificaciones. Esto explica por qué Saer alude en su poema a esa

escritura costosa, el palimpsesto
del proyecto y la redacción
trabados en lucha libre, el caos de la tipografía
como un hormiguero que se abre
en estampida sobre la nieve. ${ }^{19}$

Y esta pelea entre el proyecto y la redacción le permitía a Baudelaire explicar por qué el nombre de Borel había caído en el olvido: a pesar de sus trabajo meticuloso sobre la escritura, sus obras carecían de la unidad preconizada por aquella Philosophy of Composition de Poe que el poeta francés había traducido como La genèse d'un poème.

L'art romantique había sido iniciado por Baudelaire en francés y en prosa y Saer se encargaría de reescribirlo un siglo más tarde en versos españoles para encabezar un libro intitulado El arte de narrar (tal vez valga la pena recordar que el adjetivo romanesque resonaba todavía en el romantique de Baudelaire, de modo que el título del primer poema de puede leerse como una precisa paráfrasis del título del libro entero). Pero lo importante, para nosotros, es que este primer poema del libro nos permite leer de otro modo el último. Cuando Saer habla de "la noche" no está aludiendo solamente a la desaparición del cuerpo sino también, y sobre todo, al borramiento del nombre. Algo va a aparecer, existir o incluso, como se suele decir, "seguir vivo" en la medida que su nombre no haya sido suprimido del registro del gran Otro. Todo nos deja pensar entonces que Saer no se encontraría muy lejos de las posiciones de los mencionados Porfirio de Tiro y Justino. El genital, esa figura del génesis y de la generación, sería para ambos la metáfora de aquello sin lo cual no habría nada -ni dama ni mundo-, ese Lógos spermátikos que las estatuas de Príapo representaban, según el escolarca sirio, en las costas del Mediterráneo antes de que el cristianismo se encargase

\footnotetext{
${ }^{18}$ Juan José Saer, El arte de narrar, op. cit., p. 7.

${ }^{19}$ Ibid., p. 7.
} 
de suprimirlas y sustituirlas por las cruces. Y esto explicaría por qué Saer sustituyó al Dios del Génesis por un "pico rojo": este sustantivo permitía reunir el órgano sexual, el cincel del escultor y la embocadura de las aves.

Se comprende mejor, ahora, por qué el poeta decide enviar a su juglar, el Tiempo, a que transporte sus líneas a algún lado antes de precipitarse en la negrura. De este Papiol depende ahora que alguna estrella del cielo lleve alguna vez su nombre. De este Papiol depende también que algún día su texto se convierta en la génesis de otro, como si el tiempo llevara esos granos de polen hacia alguna flor futura. Acuérdense que así explicaba Diotima la existencia del deseo erótico en los humanos: había un ansia "de permanencia" ${ }^{20}$ que tanto puede aspirar a perpetuar la especie como a inmortalizar un nombre o una obra, ansia que se traduce en un empecinamiento del vacilante "portador del huevo"21.

"Dama, el día" puede leerse entonces como una reescritura de L'art romantique veintisiete años más tarde. Ambos poemas abordan la cuestión de la muerte de un poeta y su caída en la oscuridad pero también el misterio de la poïesis, de la creatio o de la génesis. El primero lo vincula con el "nombre" mientras el segundo prefiere evocar el "pico rojo", aunque la expresión "animal nupcial" aludiera a la inscripción de la dama en el conjunto de los seres nombrados por el hombre. Esto confirmaría a mi entender un punto que me parece crucial: los poemas de Saer son genéticos, cosmogónicos o incluso, si me perdonan la redundancia, poéticos, en el sentido de que giran en torno a la poïesis, el origen de las cosas o del mundo, el pasaje no-ser al ser, de la oscuridad a la luz, de la ausencia a la presencia, pero también, y a la inversa, de la aparición a la desaparición o de la llegada a la partida.

Este proceso de tachaduras y sustituciones, de escritura y borradura, este "palimpsesto del proyecto y la redacción / trabados en lucha libre"22, no resulta muy diferente del proceso de generación del texto en las dos dimensiones que intentamos exponer: como resultado de transformación de otros textos y como resultado de su propia transformación. Génesis paradigmática o intertextual, por un lado, que iría del hipotexto al hipertexto pasando por las eventuales variantes intermedias; génesis

\footnotetext{
${ }^{20}$ Ibid., p. 156.

${ }^{21}$ Ibid., p. 156.

${ }^{22}$ Ibid., p. 7
} 
sintagmática o intratextual, por el otro, que va, como decía Barthes, del conjunto inicial al terminal. Pensar de esta manera la generación de cualquier texto tal vez nos permita redescubrir esa sinonimia estricta entre génesis y poïesis, entre genética y poética o entre genealogía y creación, sinonimia que la imprenta contribuyó a hacernos olvidar con su estímulo a la idolatría de los autores y los genios. 